\title{
Pedestal disk resonator in potassium yttrium double tungstate
}

Martinussen, Simen, Frentrop, Raimond, Dijkstra, Meindert, Segerink, Frans, Tormo-Márquez, Victoria, et al.

Simen M. Martinussen, Raimond N. Frentrop, Meindert Dijkstra, Frans Segerink, Victoria Tormo-Márquez, José Olivares, Sonia García-Blanco, "Pedestal disk resonator in potassium yttrium double tungstate," Proc. SPIE 10535, Integrated Optics: Devices, Materials, and Technologies XXII, 105350Q (23 February 2018); doi: 10.1117/12.2289887

SPIE. Event: SPIE OPTO, 2018, San Francisco, California, United States 


\title{
Pedestal disk resonator in potassium yttrium double tungstate
}

\author{
Simen M. Martinussen*a, Raimond N. Frentrop ${ }^{\mathrm{a}}$, Meindert Dijkstra ${ }^{\mathrm{a}}{ }$ Frans Segerink $^{\mathrm{a}}$, Victoria \\ Tormo-Márquez $^{\mathrm{bc}}$, José Olivares ${ }^{\mathrm{c}}$, Sonia García-Blanco ${ }^{\mathrm{a}}$ \\ ${ }^{a}$ Optical Sciences Group, MESA+ Institute for Nanotechnology, University of Twente, P.O. Box \\ 217, 7500 AE Enschede, The Netherlands; ${ }^{\mathrm{b}}$ Centro de Micro-Análisis de Materiales, Universidad \\ Autónoma de Madrid, E-28049-Madrid, Spain; ${ }^{\mathrm{c}}$ Instituto de Óptica "Daza de Valdés", Consejo \\ Superior de Investigaciones Científicas (CSIC), Calle Serrano 121, E-28006-Madrid, Spain \\ *s.m.martinussen@utwente.nl
}

\begin{abstract}
Rare earth ion doped potassium double tungstates (e.g. $\mathrm{KY}\left(\mathrm{WO}_{4}\right)_{2}, \mathrm{KYb}\left(\mathrm{WO}_{4}\right)_{2}$, and $\left.\mathrm{KGd}\left(\mathrm{WO}_{4}\right)_{2}\right)$ have long been used as laser and amplifier materials thanks to the high achievable gain provided by the rare-earth ions. This family of host materials is also very attractive for nonlinear optics due to their high nonlinear refractive index and Raman gain. Very efficient on-chip solid state lasers, frequency combs, supercontinuum sources and Raman lasers could be realized if highrefractive index waveguides with the correct dispersion were developed.

To date, the demonstrated integrated devices in rare-earth ion doped potassium double tungstates have shown very promising results, including high gain in on-chip amplifiers and high efficiency and output power in on-chip lasers. These devices, however, were fabricated using low refractive index contrast waveguides, which are not suitable for ring resonators or to achieve anomalous dispersion. High refractive index contrast $\mathrm{KY}\left(\mathrm{WO}_{4}\right)_{2}$ waveguides with high confinement are therefore needed as building blocks for active devices.

In this work, pedestal disk resonators are proposed, based on a combination of swift ion irradiation, focused ion beam milling and a novel wet etching process. In-coupling of light into the first fabricated pedestal disks will be presented.
\end{abstract}

Keywords: integrated optics, KYW, disk resonator, wet etch, ion irradiation

\section{INTRODUCTION}

$\mathrm{KY}\left(\mathrm{WO}_{4}\right)_{2}$ is a highly attractive material for integrated optics. This is due to its numerous beneficial properties: A high refractive index of 2-2.1 gives opportunities for highly confined waveguides. In addition, the long interionic distance of $>0.4-0.5 \mathrm{~nm}[1]$ ensures weak interaction between rare earth dopant ions. This in turn allows for high doping concentrations without lifetime quenching[2]. Combined with the high absorption- and emission cross-sections[3] of rare earth ions doped into this host material, $\mathrm{KY}\left(\mathrm{WO}_{4}\right)_{2}$ shows great potential as a gain material for amplifiers and lasers[4][8].

Furthermore, $\mathrm{KY}\left(\mathrm{WO}_{4}\right)_{2}$ has a high nonlinear refractive index of up to $2.4 \times 10^{-19} \mathrm{~m}^{2} / \mathrm{W}$ at $790 \mathrm{~nm}[9]$. A high Raman gain[10] further serves to highlight the versatility of $\mathrm{KY}\left(\mathrm{WO}_{4}\right)_{2}$ for a wide range of optical applications, including Raman lasers[11]-[13].

Early work on integrated $\mathrm{KY}\left(\mathrm{WO}_{4}\right)_{2}$ structures was based on channel waveguides in rare earth ion doped layers grown by liquid phase epitaxy (LPE) on top of undoped bulk $\mathrm{KY}\left(\mathrm{WO}_{4}\right)_{2}$ substrates[14]. This has produced extremely efficient high-power lasers[15] and channel waveguide amplifiers[8] with gains of up to $935 \mathrm{~dB} / \mathrm{cm}$.

The integration of $\mathrm{KY}\left(\mathrm{WO}_{4}\right)_{2}$ onto lower refractive index substrates in order to provide high index contrast waveguides, however, is not straightforward. Using LPE as in the approach described above is not possible due to the monoclinic crystal structure[16] of the material. In order to grow a high quality optical crystalline layer the substrate and grown layer need to have matched crystal lattices[17], which limits the choice of substrate to other potassium double tungstates. 
Thanks to the lattice engineering approach described by Aravazhi et al[2], heavily $\mathrm{Yb}^{3+}$ layers have been grown on undoped $\mathrm{KY}\left(\mathrm{WO}_{4}\right)_{2}[8]$.

The achievable refractive index difference between the cladding and core when using this method is low, at $\mathrm{n}_{\text {core }}-\mathrm{n}_{\text {clad }}<2 \times 10^{-2}[17]$. This low index contrast does not allow for highly confined modes, which limits the integration density and does not permit tight waveguide bends. The large mode volume also drastically increases the power needed for nonlinear effects.

Recent work has proposed creating a thin layer of $\mathrm{KY}\left(\mathrm{WO}_{4}\right)_{2}$ by lapping and polishing a bulk $\mathrm{KY}\left(\mathrm{WO}_{4}\right)_{2}$ substrate that was bonded to a $\mathrm{SiO}_{2}$ carrier[18], [19]. A very high refractive index contrast can be achieved this way, leading to high confinement and therefore efficient gain and non-linear devices. However, the lapping and polishing process is time consuming and low yield. Irradiation of $\mathrm{KY}\left(\mathrm{WO}_{4}\right)_{2}$ with swift heavy ions (i.e., carbon at $9 \mathrm{MeV}$ ) has also been recently reported to lead to refractive index contrasts of $\mathrm{n}_{\text {core }}-\mathrm{n}_{\text {clad }} \sim 0.2$ with low propagation losses of $<1.5 \mathrm{~dB} / \mathrm{cm}$ at $1550 \mathrm{~nm}$ in slab waveguides[20].

This paper presents a novel approach to creating high index contrast $\mathrm{KY}\left(\mathrm{WO}_{4}\right)_{2}$, based on sub-surface amorphization by swift heavy ion irradiation and wet chemical etching. We demonstrate a microdisk with $40 \mu \mathrm{m}$ radius and $3.9 \mu \mathrm{m}$ underetch made using this method.

The novelty of this approach is twofold: First, it does not depend on the addition of any material in order to create a refractive index contrast in the vertical direction. This allows light to be confined to surface microstructures of a thick slab consisting of only one material. Second, we demonstrate a wet etch for $\mathrm{KY}\left(\mathrm{WO}_{4}\right)_{2}$, which has not been performed in previous literature. The etching technique is highly selective between the crystalline and amorphized material, etching the amorphous phase significantly faster.

\section{SIMULATION}

Mode calculations of the device were performed using a finite difference eigenmode (FDE) solver, using the commercial software package Lumerical MODE solutions. The disk resonator refractive index profile is represented by a rectangular slab of $\mathrm{KY}\left(\mathrm{WO}_{4}\right)_{2} 1.8 \mu \mathrm{m}$ thick, with a buried layer with index $\mathrm{n}=1.76+\mathrm{i} 10^{-4}$. The imaginary refractive index is estimated from loss measurements in swift ion irradiated slab waveguides. The resulting structure is shown in Figure 1.

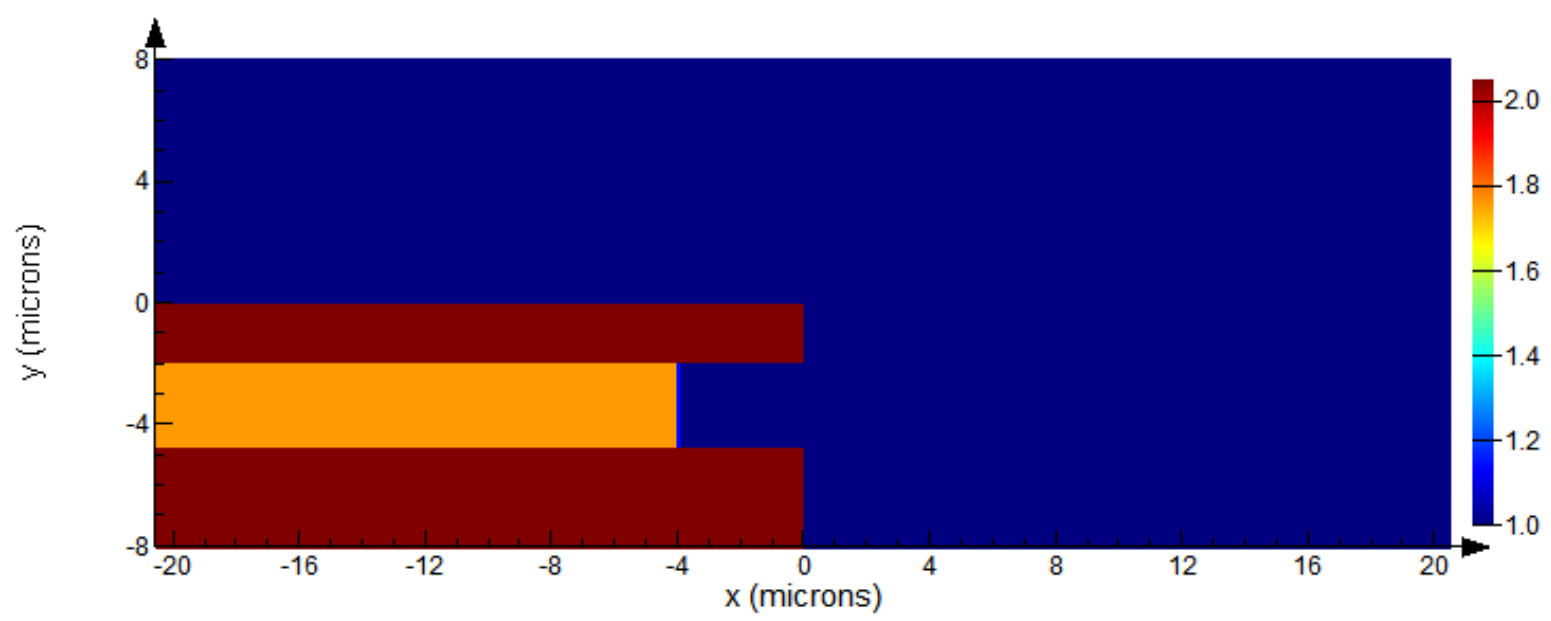

Figure 1: Refractive index of structure as simulated in Lumerical MODE.

The actual refractive index profile measured by Frentrop[20] is thus approximated by a step index profile. All the boundaries of the simulation window are represented by perfectly matched layer (PML) boundaries. The simulation window is $40 \mu \mathrm{m}$ wide in the $\mathrm{x}$ direction and $15 \mu \mathrm{m}$ wide in the y direction. It has been found by convergence testing that this is large enough to not affect the effective index of the calculated modes. It is important to note that as the disks are $80 \mu \mathrm{m}$ in diameter, only a portion of the disk is in the simulation region. This is not an issue, as the mode is confined to the outer edge. 
In the simulation, the effective refractive index $\left(\mathrm{n}_{\text {eff }}\right)$, propagation loss and effective mode area $\left(\mathrm{A}_{\mathrm{eff}}\right)$ of the fundamental TE and TM modes are calculated as a function of underetch. The underetch is varied from 0 to $6 \mu \mathrm{m}$ in steps of $50 \mathrm{~nm}$. The effective mode area, $A_{\text {eff }}$, is defined[21] as

$$
\mathrm{A}_{\mathrm{eff}}=\frac{\left(\int|H|^{2} d A\right)^{2}}{\int|H|^{4} d A} .
$$

Figure 2 (a) shows the effective refractive index of the two fundamental modes. There is an avoided crossing (also known as an anti-crossing) centered at $\sim 1.1 \mu \mathrm{m}$ of underetch. At this point neither mode is pure TE or TM. The two modes exchange their polarization state after the avoided crossing, as can be seen in the TE fraction shown on the right axis of Figure 2 (a).

Figure 2 (b) shows the propagation loss as a function of underetch. As expected, increasing the underetch reduces interaction with the barrier, which is the main source of loss in this simulation. It is important to note that other sources of propagation losses, such as surface roughness, were not taken into account in this simulation. As a verification, a simulation in which the barrier material was replaced with gold was performed. A loss of $7.3 \times 10^{-6} \mathrm{~dB} / \mathrm{cm}$ was obtained for an underetch of $4 \mu \mathrm{m}$, indicating minimal interaction of the mode with the barrier.

Finally, Figure 3 shows the effective mode area as a function of underetch. While the variation is not very large, spanning from around $2.3 \mu \mathrm{m}^{2}$ to $2.6 \mu \mathrm{m}^{2}$, underetch is beneficial for reducing the effective mode area. The TM polarized mode is at all times better confined than the TE mode.

The simulations show that increasing underetch is beneficial to the disk performance, decreasing both the propagation losses and the effective mode area. For the first prototype, a disk radius of $40 \mu \mathrm{m}$ with underetch of $4 \mu \mathrm{m}$ was selected. This geometry exhibits a group index of 2.05 , which leads to a free spectral range of $4.66 \mathrm{~nm}$.
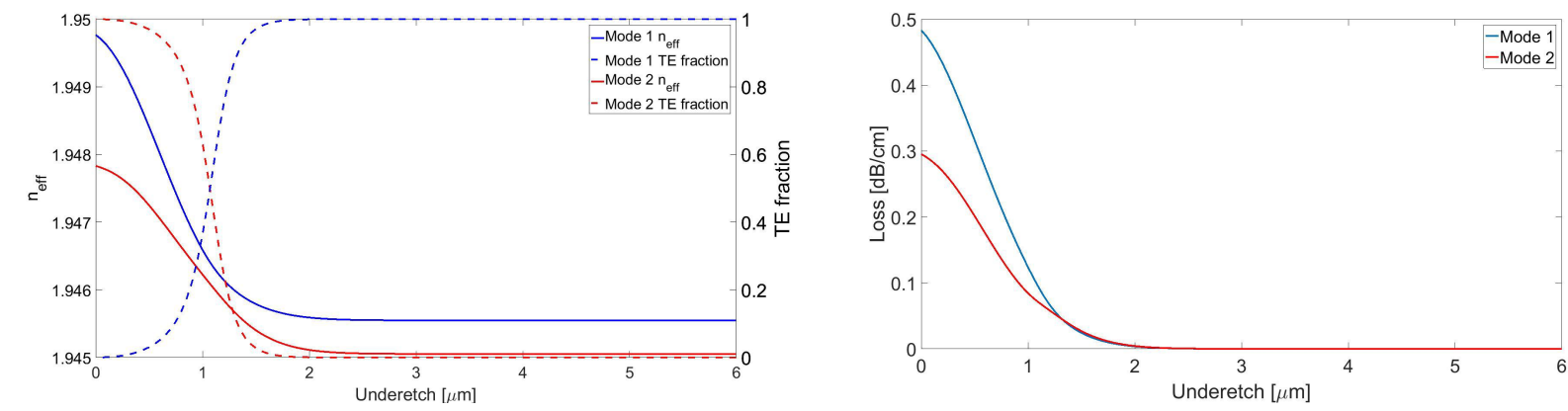

Figure 2: (a) Effective refractive index and TE fraction as a function of underetch depth. (b) Propagation loss as a function of underetch depth.

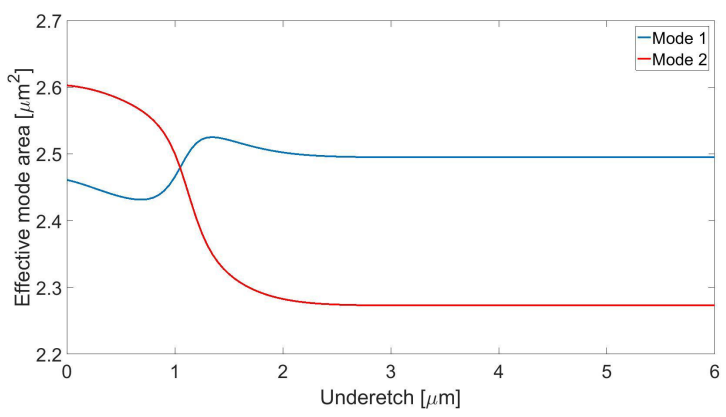

Figure 3: Effective mode area as a function of underetch depth. 


\section{EXPERIMENTAL METHODS}

The $\mathrm{KY}\left(\mathrm{WO}_{4}\right)_{2}$ substrates used in this work were obtained from Altechna (LT). The substrates have dimensions 10x10x1 $\mathrm{mm}^{3}$, with edges along the crystalline $a$ and $c$ axes, and the $b$ plane polished to optical quality, (i.e. rms $\sim 1.5 \mathrm{~nm}$ )[2].

\section{Amorphization}

Ion irradiation was performed in the $5 \mathrm{MV}$ electrostatic tandem accelerator of the Centro de Micro-Análisis de Materiales (CMAM) of the Universidad Autónoma de Madrid (UAM). The sample was irradiated with carbon ions at an energy of $9 \mathrm{MeV}$ and a fluence of $3 \times 10^{14}$ ions $/ \mathrm{cm}^{2}$. The incident ions penetrate several micrometers into the material, creating a region of partial amorphization, with most damage to the crystal structure between $2 \mu \mathrm{m}$ and $5 \mu \mathrm{m}$ from the surface. Full details of the ion implantation process are given by Frentrop et al. [20]

After irradiation and patterning (see next sub-section), the sample was annealed at $350^{\circ} \mathrm{C}$. The annealing step serves to recrystallize the sample surface, returning it to a higher refractive index, closer to the unirradiated sample and reducing the defects induced by the incident ions, which results in point and color center formation. The m-lines technique was performed using a Metricon 2010/M system with laser sources at $633 \mathrm{~nm}, 830 \mathrm{~nm}, 1300 \mathrm{~nm}$ and $1550 \mathrm{~nm}$, to extract the refractive index profile of the slab waveguides formed using this technique.

\section{Patterning}

$\mathrm{KY}\left(\mathrm{WO}_{4}\right)_{2}$ is chemically inert and resists chemical etching. This makes surface structuring by reactive ion etching (RIE) challenging, as chemically active gases such as $\mathrm{SF}_{6}$ and $\mathrm{CHF}_{3}$ do not attack the substrate. For this reason, only physical sputtering remains as a viable etch mechanism. While this can be implemented using Ar in an RIE system[22], we have opted for structuring using focused ion beam (FIB) milling. The milling was performed before the annealing step.

Before patterning, the sample was covered with a $200 \mathrm{~nm}$ thick layer of $\mathrm{SiO}_{2}$ in an Oxford Plasmalab 80 PECVD. Afterward, $5 \mathrm{~nm}$ of $\mathrm{Au} / \mathrm{Pd}$ was sputtered onto the surface using a Polaron Bio-Rad E5400 sputter coater. The Au/Pd layer acts as a conductive layer in order to improve FIB and SEM resolution and avoid beam drifting due to charging.

The FIB used is an FEI Nova 600 NanoLab. Rings were milled into the $\mathrm{KY}\left(\mathrm{WO}_{4}\right)_{2}$ substrate at an acceleration voltage of $30 \mathrm{kV}$ and a current of $21 \mathrm{nA}$. The rings had an outer diameter of $100 \mu \mathrm{m}$, an inner diameter of $80 \mu \mathrm{m}$, and a depth of 5 $\mu \mathrm{m}$. After milling, the sample was immersed in a buffered $7 \% \mathrm{HF}$ etch to lift off the $\mathrm{SiO}_{2}$ and metal layers.

\section{Wet etching}

While crystalline $\mathrm{KY}\left(\mathrm{WO}_{4}\right)_{2}$ resists chemical etching, amorphous $\mathrm{KY}\left(\mathrm{WO}_{4}\right)_{2}$ can be dissolved in $\mathrm{HCl}$. This differential etching between crystalline and amorphous $\mathrm{KY}\left(\mathrm{WO}_{4}\right)_{2}$ can be utilized to create an underetch after the FIB milling has exposed the amorphized layer. The sample was etched in $20 \% \mathrm{HCl}$ at room temperature for 2 hours.

\section{Characterization}

The sample was visually inspected by SEM in the FIB/SEM system. Light was then coupled into the sample perpendicularly, using a $633 \mathrm{~nm}$ He-Ne laser focused through a 100x objective with NA=0.9. The sample was imaged simultaneously.

\section{RESULTS}

\section{Amorphization}

The annealing procedure has been found to almost completely undo any damage to the crystal structure of the nearsurface region. The interface between the crystalline and amorphous regions is $\sim 2 \mu \mathrm{m}$ from the surface after the annealing step, with a heavily amorphized region extending from $2 \mu \mathrm{m}$ down to $5 \mu \mathrm{m}$ below the surface. Total propagation losses of the planar waveguide modes are $1.5 \mathrm{~dB} / \mathrm{cm}$ at $1550 \mathrm{~nm}$. Potential reasons for these losses are absorption and scattering in the amorphized region, inhomogeneities at the interface and point defects and color centers in the guiding layer. 


\section{Fabrication}

Figures 4 (a) and (b) show the ring structure before and after annealing and wet etching. It is clear from the outer edge of the trench that the etch has been successful in carving out an empty space underneath the edge of the disk. Along the inner edge, however, there are visible residues. This may cause losses due to interaction with the lossy amorphized region if the residue inhibits a proper underetch. Furthermore, the residues appear rough, which may cause additional scattering losses.

Figure 5 shows a successfully underetched cross section from a test structure milled $7 \mu \mathrm{m}$ deep. The thickness of the crystalline slab is $2 \mu \mathrm{m}$, the vertical depth of the etched region is is $2.7 \mu \mathrm{m}$ and the horizontal etch depth is $3.9 \mu \mathrm{m}$ on the top of the amorphous region. On the bottom of the amorphous region the etch depth is $3.8 \mu \mathrm{m}$. All the distances are measured by SEM and are assumed to have an accuracy of $\pm 100 \mathrm{~nm}$ due to indistinct boundaries and charging effects.

The wet etch has not been found to attack crystalline $\mathrm{KY}\left(\mathrm{WO}_{4}\right)_{2}$ to any significant degree. This is justified by inspecting the corner in Figure 5, which is sharp. Assuming the acid to only etch the amorphous region, the etch rate is calculated to be $\sim 33 \mathrm{~nm} / \mathrm{min}$.
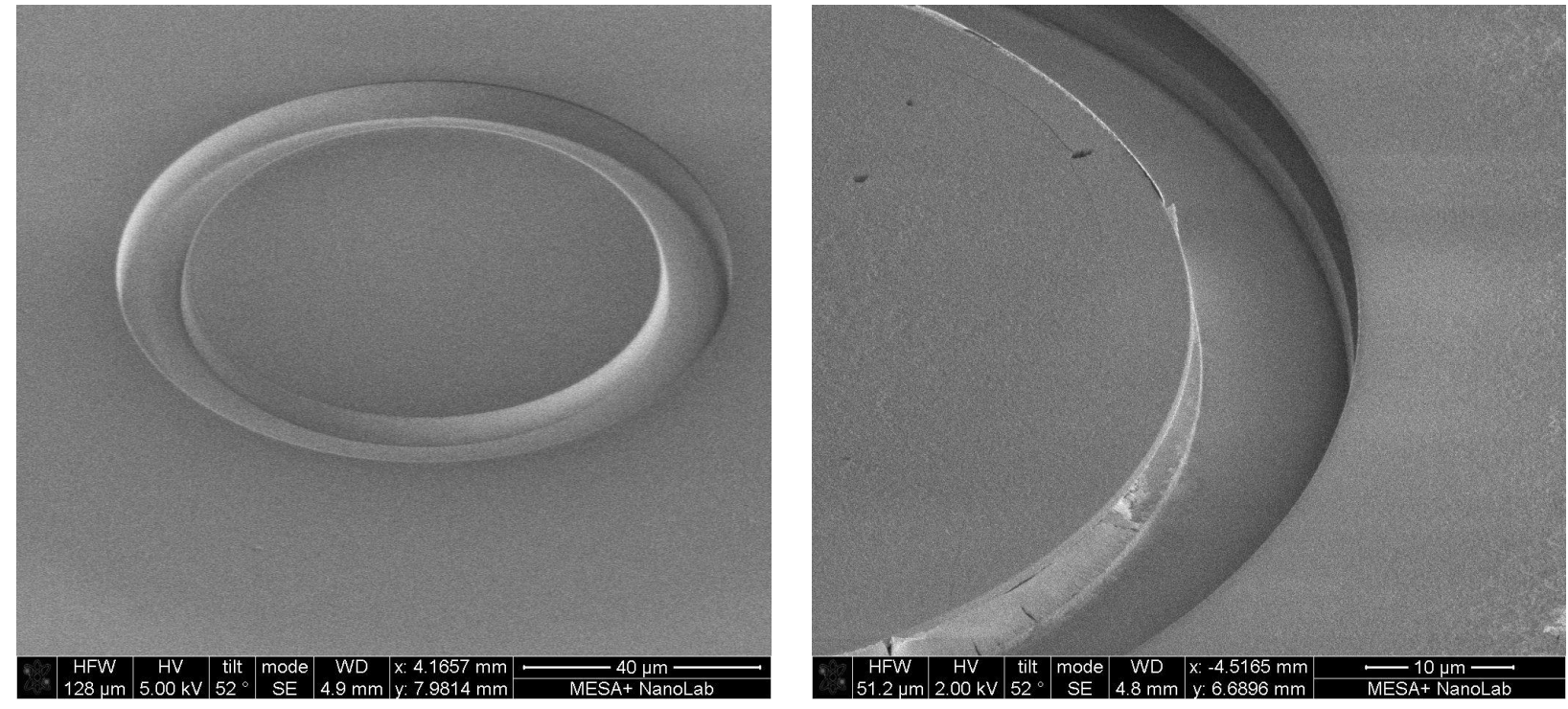

Figure 4: a) SEM image of the FIB milled disk before annealing and wet etching. b) The same structure after annealing and wet etching. Some regions have good underetch, while unetched residues remain in other areas. 


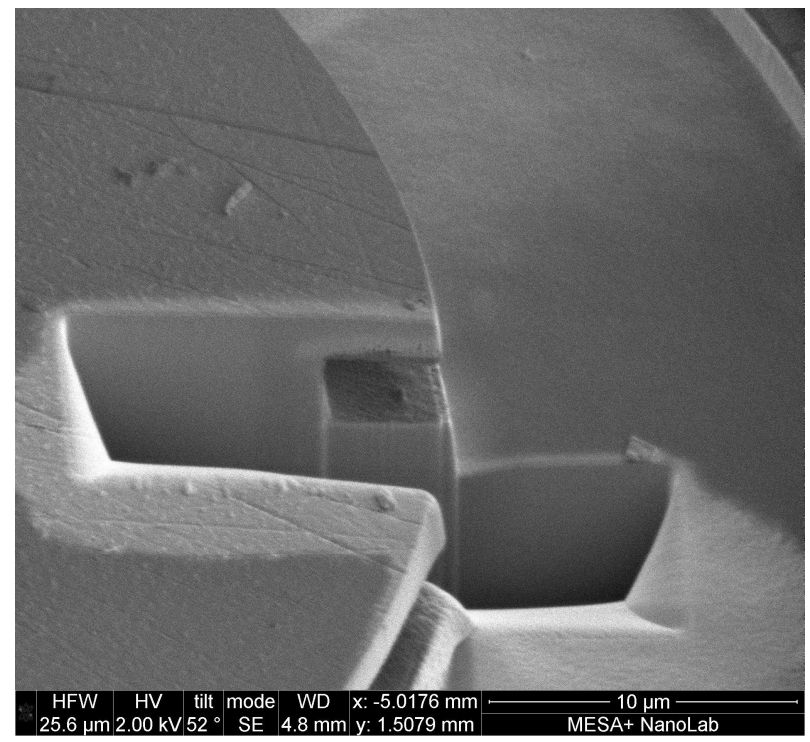

Figure 5: FIB cross section cut of a test structure with successful underetching. The underetch starts at $2 \mu \mathrm{m}$ from the surface of the sample, extends $2.7 \mu \mathrm{m}$ in the vertical direction and is $3.9 \mu \mathrm{m}$ deep in the horizontal direction.

\section{Characterization}

Figure 6 shows light propagating in the finished device. Many scattering points are visible along the perimeter of the disk, probably due to the fabrication defects and non-uniformity of the wet etching process discussed above. Illumination away from the disk perimeter does not cause any significant response. This measurement represents the first propagation on a $\mathrm{KY}\left(\mathrm{WO}_{4}\right)_{2}$ microdisk structure.

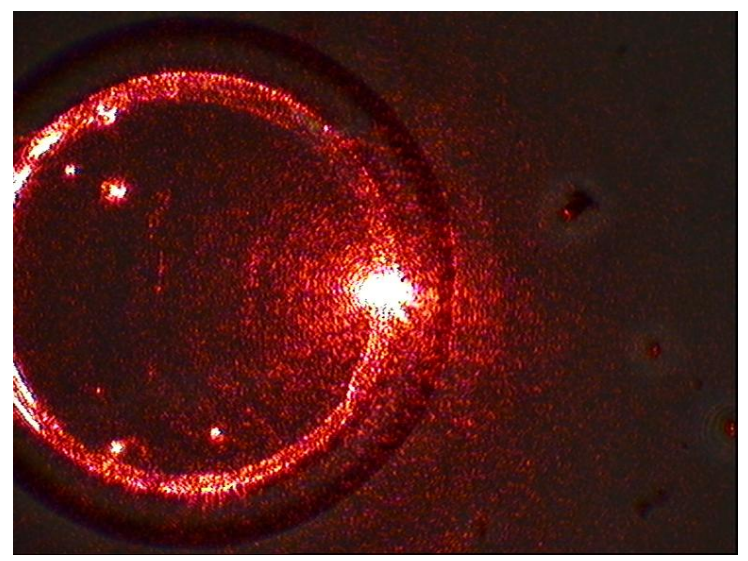

Figure 6: Incoupling of light through an objective perpendicular to the disk.

\section{CONCLUSION}

We have successfully fabricated a $\mathrm{KY}\left(\mathrm{WO}_{4}\right)_{2}$ microdisk with geometrical parameters optimized by mode simulations. The microdisk was manufactured using two novel techniques, namely swift ion irradiation to produce a buried amorphous barrier with low refractive index, and a wet etch with high selectivity between amorphous and crystalline $\mathrm{KY}\left(\mathrm{WO}_{4}\right)_{2}$. The differential etch has a rate of $32 \mathrm{~nm} / \mathrm{min}$. We have successfully coupled light into the disk from above using a 100x objective. 


\section{ACKNOWLEDGEMENTS}

The research leading to these results has received funding from the European Research Council under ERC Consolidator grant RENOS, project number 648978.

[1] Krygin, I. M., Prokhorov, A. D., D'yakonov, V. P, Borowiec, M. T., and Szymczak, H., "Spin-spin interaction of $\mathrm{Dy}^{3+}$ ions in $\mathrm{KY}\left(\mathrm{WO}_{4}\right)_{2}$ " Phys. Solid State 44, no. 8, 1587-1596 (2002).

[2] Aravazhi, S., Geskus, D., van Dalfsen, K., Vázquez-Córdova, S. A., Grivas, C., Griebner, U., García-Blanco, S.M., and Pollnau, M., "Engineering lattice matching, doping level, and optical properties of $\mathrm{KY}\left(\mathrm{WO}_{4}\right)_{2}$ : $\mathrm{Gd}, \mathrm{Lu}, \mathrm{Yb}$ layers for a cladding-side-pumped channel waveguide laser" Appl. Phys. B 111(3), 433-446 (2013)

[3] Yong, Y., Aravazhi, S., Vázquez-Córdova, S., Carvajal, J., Díaz, F., Herek, J., García-Blanco S.M., and Pollnau, M., "Direct confocal lifetime measurements on rare-earth-doped media exhibiting radiation trapping," Opt. Mater. Express 7, 527-532 (2017).

[4] Kovalyov, A. A., Preobrazhenskii, V. V., Putyato, M. A., Pchelyakov, O. P., Rubtsova, N. N., Semyagin, B. R., Kisel V.E, Kuril'chik, S. V, and Kuleshov, N. V. "115 fs pulses from $\mathrm{Yb}^{3+}: \mathrm{KY}\left(\mathrm{WO}_{4}\right)_{2}$ laser with low loss nanostructured saturable absorber," Laser Phys. Lett. 8(6), 431-435 (2011).

[5] Lagatsky, A. A., Fusari, F., Calvez, S., Gupta, J. A., Kisel, V. E., Kuleshov, N. V., Brown, C. T. A, Dawson, M. D., and Sibbett, W., "Passive mode locking of a Tm, Ho:KY $\left(\mathrm{WO}_{4}\right)_{2}$ laser around $2 \mu \mathrm{m}$," Opt. Lett. 34(17), 2587-2589 (2009)

[6] Brunner, F., Spühler, G. J., Aus Der Au, J. A., Krainer, L., Morier-Genoud, F., Paschotta, R., Lichtenstein, N., Weiss, S., Harder, C., Lagatsky, A. A., Abdolvand, A. Kuleshov, N. V., and Keller, U.. "Diode-pumped femtosecond $\mathrm{Yb}: \mathrm{KGd}$ (WO4 2 laser with 1.1-W average power," Opt Lett 25(15), 1119-1121 (2000)

[7] Griebner, U., Rivier, S., Petrov, V., Zorn, M., Erbert, G., Weyers, M., Mateos, X., Aguilo, M., Massons, J., and Díaz, F., "Passively mode-locked Yb:KLu (WO W $_{2}$ oscillators," Opt Exp. 13(9), 3465-3470 (2005)

[8] Geskus, D., Aravazhi, S., García-Blanco, S. M, and Pollnau, M., "Giant Optical Gain in a Rare-Earth-Ion-Doped Microstructure," Adv. Mater. 24, no. 10, OP19-OP22 (2012)

[9] Thilmann, N., Strömqvist, G., Pujol, M. C., Pasiskevicius, V., Petrov, V., and Díaz, F., "Nonlinear refractive indices in $\mathrm{Yb}^{3+}$-doped and undoped monoclinic double tungstates $\mathrm{KRE}\left(\mathrm{WO}_{4}\right)_{2}$ where $\mathrm{RE}=\mathrm{Gd}, \mathrm{Y}, \mathrm{Yb}, \mathrm{Lu}$," Appl. Phys. B 96, no. 2-3, 385-392, (2009)

[10] Piper, J. A. and Pask, H. M., "Crystalline Raman Lasers,” IEEE J. Sel. Top. Quantum Electron. 3, no. 13, 692-704 (2007)

[11] Cong, Z., Liu, Z., Qin, Z., Zhang, X., Zhang, H., Li, J., Haohai, Y., and Wang, W. "LD-pumped actively Qswitched Nd:KLu ( $\left(\mathrm{WO}_{4}\right)_{2}$ self-Raman laser at 1185nm," Opt. \& Laser Tech. 73, 50-53 (2015)

[12]Petrov, V., Cinta Pujol, M., Mateos, X., Silvestre, O., Rivier, S., Aguilo, M., Sole, R. M., Liu, J., Griebner, U., and Diaz, F., "Growth and properties of $\mathrm{KLu}\left(\mathrm{WO}_{4}\right)_{2}$, and novel ytterbium and thulium lasers based on this monoclinic crystalline host," Laser \& Photon. Rev. 1, no. 2, 179-212 (2007)

[13] Kaminskii, A. A., Klevtsov, P. V., Li, L., and Pavlyuk, A. A., "Stimulated emission from $\mathrm{KY}\left(\mathrm{WO}_{4}\right)_{2}: \mathrm{Nd}^{3+}$ crystal laser," Phys. Stat. Sol. (a) 5, no. 2, K79-K81 (1971)

[14] Geskus, D., Aravazhi, S., Grivas, C., Wörhoff, K., and Pollnau, M., "Microstructured $\mathrm{KY}\left(\mathrm{WO}_{4}\right)_{2}: \mathrm{Gd}^{3+}, \mathrm{Lu}^{3+}, \mathrm{Yb}^{3+}$ channel waveguide laser," Opt. Exp. 18, no. 9, 8853 (2010)

[15] van Dalfsen, K., Aravazhi, S., Grivas, C., García-Blanco, S. M., and Pollnau, M., "Thulium-doped channel waveguide laser with $1.6 \mathrm{~W}$ of output power and exceeding $80 \%$ slope efficiency," Adv. Solid State Lasers Cong. paper ATu1A.8. (2013)

[16] Mateos, X., Solé, R., Gavaldà, J., Aguiló, M., Massons, J., and Díaz, F., "Crystal growth, optical and spectroscopic characterisation of monoclinic $\mathrm{KY}\left(\mathrm{WO}_{4}\right)_{2}$ co-doped with $\mathrm{Er}^{3+}$ and $\mathrm{Yb}^{3+}$," Opt. Mat., vol. 28, no. 4, 423-431, (2006)

[17] Romanyuk, Y., "Liquid-phase epitaxy of doped $\mathrm{KY}\left(\mathrm{WO}_{4}\right)_{2}$ layers for waveguide lasers," $\mathrm{PhD}$ thesis, École Polytechnique Fedérale de Lausanne (2005)

[18] Sefunc, M. A., Segerink, F., and Garcia-Blanco, S. M., "High index contrast potassium double tungstate waveguides towards efficient rare-earth ion amplification on-chip," proc. SPIE 9365, p. 93650P (2015)

[19] van Emmerik, C. I., Martinussen, S. M., Mu, J-F., Dijkstra, M., Kooijman, R., and Garcia-Blanco, S., "A novel polishing stop for accurate integration of potassium yttrium double tungstate on silicon dioxide," Proc. SPIE 10535, 10535-27 (2018) 
[20] Frentrop, R., Dijkstra, M., Tormo-Marquez, V., Olivares, J., and Garcia-Blanco,. S. M., "High-contrast slab waveguide fabrication in $\mathrm{KY}\left(\mathrm{WO}_{4}\right)_{2}$ by swift heavy ion irradiation," Proc. SPIE 10535, 10535-22 (2018)

[21] Agrawal, G. P., [Nonlinear Fiber Optics], Academic Press (2013)

[22] Martinussen, S. M., Dijkstra, M., and Garcia-Blanco, S. M., "Reducing redeposition on KYW waveguides through hard mask engineering,” Proc. Symp. IEEE Phot. Soc. Benelux (2017)

Proc. of SPIE Vol. 10535 105350Q-8

Downloaded From: https://www.spiedigitallibrary.org/conference-proceedings-of-spie on 16 Apr 2020 Terms of Use: https://www.spiedigitallibrary.org/terms-of-use 